\title{
Prognostic discrimination of subgrouping node-positive endometrioid uterine cancer: location vs nodal extent
}

\author{
DS Kapp*,I, TK Kiet ${ }^{2}$ and JK Chan ${ }^{2}$ \\ 'Department of Radiation Oncology, Stanford University School of Medicine, Cancer Center, 875 Blake Wilbur Drive, Stanford, CA 94305, USA; '2Division \\ of Gynecologic Oncology, Department of Obstetrics, Gynecology and Reproductive Sciences, University of California, San Francisco School of Medicine, \\ Helen Diller Family Comprehensive Cancer Center, 1600 Divisadero Street, San Francisco, CA 94 I 43, USA
}

BACKGROUND: The 2009 International Federation of Gynecologists and Obstetricians elected to substage patients with positive retroperitoneal lymph nodes as IIIC I (pelvic lymph node metastasis only) and IIIC 2 (paraaortic node metastasis with or with positive pelvic lymph nodes). We have investigated the discriminatory ability of subgrouping patients with retroperitoneal nodal involvement based on location, number, and ratio of positive nodes.

METHODS: For 1075 patients with stage IIIC endometrioid corpus cancer abstracted from the Surveillance, Epidemiology, and End Results databases for 2003-2007, Kaplan-Meier analyses, Cox proportional hazard models, and other quantitative measures were used to compare the prognostic discrimination for disease-specific survival (DSS) of nodal subgroupings.

RESULTS: In univariate analysis, the 3-year DSS were significantly different for subgroupings by location (IIIC I vS IIIC 2; 80.5\% vs 67.0\%, respectively, $P=0.00 \mathrm{I}$ ), lymph node ratio ( $\leqslant 23.2 \%$ vs $>23.2 \%$; $80.8 \%$ vs $67.6 \% ; P<0.00 \mathrm{I}$ ), and number of positive lymph nodes $(I, 2-5,>5 ; 79.5,75.4,62.9 \%, P=0.016)$. The ratio of positive nodes showed superior discriminatory substaging in Cox models. CONCLUSION: Subgrouping of stage IIIC patients by the ratio of positive nodes, either as a dichotomized or continuous parameter, shows the strongest ability to discriminate the survival, controlling for other confounding factors.

British Journal of Cancer (20 I I) 105, I I37-I I43. doi:I0.1038/bjc.201 I.336 www.bjcancer.com

Published online 13 September 201 I

(c) 20II Cancer Research UK

Keywords: uterine cancer; positive lymph nodes; substaging; node location; node ratio

Uterine cancer is the most common pelvic gynaecologic malignancy in the United States. Based on a Gynaecologic Oncology Group study of surgical staging of clinical stage I endometrial cancer, $9.3 \%$ of patients had positive pelvic lymph node involvement whereas $5.5 \%$ had positive paraaortic lymph nodes, with a total of $11.3 \%$ having either pelvic and/or paraaortic retroperitoneal metastasis (Creasman et al, 1987). The most recent modification of the International Federation of Gynecologists and Obstetricians (FIGO) staging system for endometrial cancer has elected to subclassify patients with retroperitoneal lymph node involvement (without other sites of distant metastasis) into two subgroups based on the location of the metastatic lymph nodes. Patients with only pelvic lymph node involvement are staged as IIIC 1 whereas those with positive paraaortic lymph node (with or without positive pelvic lymph nodes) are stage IIIC 2 (Pecorelli, 2009). Two recent Surveillance, Epidemiology, and End Results (SEER)-based analyses have demonstrated worse outcome for patients with stage IIIC 2 vs IIIC 1 disease (Lewin et al, 2010; Cooke et al, 2011). However these studies were limited because there was no accounting for confounders such as number of positive nodes (Touboul et al, 2001; Takeshima et al, 2006; Fujimoto et al, 2009) or lymph node ratio, which have also been shown to be

*Correspondence: Dr DS Kapp; E-mail: dskapp@stanford.edu Received 9 May 201 I; revised 27 July 2011; accepted 2 August 201 I; published online 13 September 20 I | prognostically important (Tang et al, 1998; Mariani et al, 2001a; Yasunaga et al, 2003; Chan and Kapp, 2007; Chan et al, 2007).

In this current study, we investigated the prognostic significance of the new subdivision of stage IIIC disease and compared the discriminatory ability of location, number, and ratio of positive lymph nodes controlling for other confounding factors. The identification of other subgrouping based on characteristics of lymph node involvement may have therapeutic implications.

\section{MATERIALS AND METHODS}

The SEER Program database of the United States National Cancer Institute for endometrioid uterine cancer patients during the period from 1 January 2004 to 31 December 2007 was utilised (SEER, 2010, http://www.seer.cancer.gov). Patients with nonendometriod histologies were excluded. This time period was selected because in earlier periods patients with involved paraaortic lymph nodes were included with patients with stage IV disease. Of the 22907 patients, 1235 (5.4\%) had IIIC disease. A total of 160 patients who lacked information on lymph node dissection and/or lymph node distribution were excluded, leaving 1075 patients as the study cohort. All but four patients underwent some type of hysterectomy (three had no hysterectomy and for one the type of uterine surgery was not specified).

Data on demographic, clinical-pathological, and treatment parameters were abstracted. Patients were divided into nodal 
subgroups based on the number of positive nodes $(1,2-5$, and $>5$ nodes), total number of nodes examined ( $\leqslant 10,11-20,>20)$, and ratio of positive nodes, expressed as the percentage of positive lymph nodes to the total number of nodes examined $(\leqslant 10 \%$, $10-50 \%,>50 \%$ ), as in our previous study (Chan et al, 2007). In addition, the nodal parameters were dichotomized by the median number of positive nodes $(1,>1)$ and ratio of positive nodes $(\leqslant$ or >average $(23.2 \%)$ ) to permit comparison with the new FIGO dichotomized stage grouping.

The primary endpoint of the study was the endometrial cancer disease-specific survival (DSS). Time to death was censored in patients who died from causes other than uterine cancer. Survival analyses were performed using the Kaplan-Meier method. Pearson's $\chi^{2}$ - and Student's $t$-test were employed to compare distributions of parameters between subgroups. Two-sided $P$-values of $<0.05$ were considered statistically significant. Pearson correlations were used to investigate for multiple colinearities between the subgrouping of lymph nodal involvement based on location, number of positive nodes, and ratio of positive nodes. Because of the potential correlation between the various subgroupings of lymph nodes, separate stepwise Cox regression models were employed entering only one of the three subgroupings of the lymph nodes in each model. Because preliminary analysis demonstrated a significantly higher number of positive lymph nodes for patients with IIIC 2 s IIIC 1 disease, comparisons were also made between the three nodal subgroupings for a subset of 487 patients with only one positive lymph node. Three additional quantitative measures were used to compare the prognostic discrimination for DSS for nodal subgrouping (Gimotty et al, 2005). All statistical analyses were performed using the SPSS Statistics GradPack 17.0, Release 17.0.0 (3 August 2008, IBM, Armonk, NY, USA).

\section{RESULTS}

The demographic and clinical characteristics of the 1075 patients with stage IIIC endometrioid corpus cancers are delineated in Table 1. A total of 725 patients $(67.4 \%)$ had positive pelvic nodes only (stage IIIC 1) whereas $350(32.6 \%)$ had paraaortic node involvement with or without positive pelvic nodes (stage IIIC 2). The average number of lymph nodes examined was 17.3 (range: $1-90)$. The average number of positive nodes was three (range: $1-82$ ) and the average lymph node ratio was $23.2 \%$ (range $0.01-100 \%)$. Adjuvant radiation therapy was given to $638(59.3 \%)$ of the patients. The median follow-up was 18 months (mean 19.4, range $0-47$ ).

In univariate analysis, race (Black and unknown or others, $P=0.042)$, higher grade $(P<0.001)$, lack of adjuvant radiation therapy $(P<0.001)$, not married patients $(P<0.005)$, and nodal parameters including lower number of lymph nodes examined $(P=0.001)$, higher number of positive lymph nodes $(P=0.016)$, higher ratio of positive lymph nodes $(P<0.001)$ and FIGO substage (stage IIIC 2 vs IIIC $1, P=0.001$ ) were significantly associated with poorer DSS (Table 2). The 3-year DSS for stage IIIC 1 was $80.5 \%$ vs $67.0 \%$ for IIIC $2(P=0.001$; Figure $1 \mathrm{~A})$. The 3 -year DSS for $1,2-5$ or $>5$ positive nodes were $79.5 \%, 75.4 \%$, and $62.9 \%$, respectively $(P=0.016$, Figure $1 \mathrm{~B})$. Based on ratio of positive lymph nodes to total lymph nodes examined (average $=23.2 \%$ ), the 3 -year DSS was $80.8 \%$ for $\leqslant$ average ratio $v s 67.6 \%>$ average ratio $(P<0.001$; Figure 1C). For patients divided into three groups based on lymph node ratio $(10 \%, 10-50 \%$, and $>50 \%)$, the 3 -year DSS decreased with increasing lymph node ratio $(82.9 \%, 73.9 \%$, and $64.5 \%$ respectively, $P<0.001$, Figure 1D).

Significantly poorer DSS was seen in higher grade tumours $(P<0.001)$ and with the lack of adjuvant radiation $(P<0.001)$. In a separate analysis (data not shown) the patients were grouped by number of lymph nodes examined $(<10,10-20, \geqslant 20)$. Even for
Table I Patient demographic and clinical characteristics

\begin{tabular}{|c|c|}
\hline Parameters & $\mathbf{N}(\%)$ \\
\hline \multicolumn{2}{|l|}{ Age at diagnosis (average: 62, range: 28-95) (years) } \\
\hline$<62$ & $515(47.9)$ \\
\hline$\geqslant 62$ & $560(52.1)$ \\
\hline \multicolumn{2}{|l|}{ Marital status ${ }^{\mathrm{a}}$} \\
\hline Married & $538(51.0)$ \\
\hline Not married & $516(49.0)$ \\
\hline \multicolumn{2}{|l|}{ Race } \\
\hline White & $917(85.3)$ \\
\hline Black & $68(6.3)$ \\
\hline Asian & $79(7.3)$ \\
\hline Unknown or other & II (1.0) \\
\hline \multicolumn{2}{|l|}{ Grade } \\
\hline । & $169(15.7)$ \\
\hline 2 & $429(39.9)$ \\
\hline 3 & $397(36.9)$ \\
\hline Unknown & $80(7.4)$ \\
\hline \multicolumn{2}{|l|}{ Location of positive regional nodes } \\
\hline Pelvic (stage IIIC I) & $725(67.4)$ \\
\hline Paraaortic with or without pelvic (stage IIIC 2) & $350(32.6)$ \\
\hline \multicolumn{2}{|l|}{ Number of positive nodes (average: 3 , range: 1 -82) } \\
\hline । & $487(45.3)$ \\
\hline $2-5$ & $49 \mid(45.7)$ \\
\hline$>5$ & $97(9.0)$ \\
\hline \multicolumn{2}{|c|}{ Total number of nodes examined (average: 17.3, range: 1-90) } \\
\hline$\leqslant 10$ & $376(35.0)$ \\
\hline $11-20$ & $346(32.2)$ \\
\hline$>20$ & $353(32.8)$ \\
\hline \multicolumn{2}{|c|}{ Ratio of positive nodes (average: $23.2 \%$, range: $0.01-100 \%$ ) } \\
\hline$\leqslant$ Average & $729(67.8)$ \\
\hline$>$ Average & $346(32.2)$ \\
\hline \multicolumn{2}{|c|}{ Ratio of positive nodes (average: $23.2 \%$, range: $0.01-100 \%$ ) } \\
\hline$\leqslant 10 \%$ & $402(37.4)$ \\
\hline $10-50 \%$ & $567(52.7)$ \\
\hline$>50 \%$ & $106(9.9)$ \\
\hline \multicolumn{2}{|l|}{ Adjuvant radiation } \\
\hline No & $437(40.7)$ \\
\hline Yes & $638(59.3)$ \\
\hline
\end{tabular}

aMarital status: total $N=1054$ due to unknowns; not married includes single, divorced, separated, and widowed.

the subgroups with $\geqslant 20$ nodes examined, significantly lower DSS was seen with increasing number of positive nodes, stage III C2 vs stage III $\mathrm{C} 1$, and higher ratio of positive nodes $(P<0.001)$.

Stage IIIC 2 patients had higher number of positive nodes $(P<0.001)$, higher ratio of positive nodes $(P<0.001)$, and a higher number of reported lymph nodes $(P<0.0001)$ than for stage IIIC 1 patients (Table 3 ).

On multivariate analysis, grade of tumour $(P<0.001)$, ratio of positive nodes $(P=0.005)$, adjuvant radiation $(P<0.001)$, and marital status $(P<0.01)$ were independent factors associated with DSS whereas location of the positive nodes, number of positive nodes, and number of nodes examined were not significant (Table 4). The hazard ratio for the ratio of positive nodes as a continuous variable was 3.10 .

Pearson correlation coefficients were employed to look for colinearity between the subgroupings of positive lymph nodes (location, number of positive nodes, and node ratios) and showed small correlations between these variables $(0.106,0.263$, and 0.321 , respectively). Repeat multivariate analyses were performed by 
Table 2 Patient parameters associated with disease-specific survival

\begin{tabular}{|c|c|c|}
\hline Parameters & $\begin{array}{c}\text { 3-year } \\
\text { DSS (\%) }\end{array}$ & $P$-value \\
\hline $\begin{array}{l}\text { Age (average: } 62 \text {, range: } 28-95 \text { ) (years) } \\
\quad<62 \\
\quad \geqslant 62\end{array}$ & $\begin{array}{l}79.7 \pm 2.7 \\
73.2 \pm 2.9\end{array}$ & 0.078 \\
\hline $\begin{array}{l}\text { Marital status }^{\mathrm{a}} \\
\text { Married } \\
\text { Not married }\end{array}$ & $\begin{array}{l}80.4 \pm 2.7 \\
72.0 \pm 3.0\end{array}$ & 0.005 \\
\hline $\begin{array}{l}\text { Race } \\
\text { White } \\
\text { Black } \\
\text { Asian } \\
\text { Unknown or other }\end{array}$ & $\begin{array}{l}77.6 \pm 2.1 \\
57.0 \pm 9.0 \\
79.4 \pm 7.5 \\
66.7 \pm 27.2\end{array}$ & 0.042 \\
\hline $\begin{array}{l}\text { Grade } \\
\quad 1 \\
2 \\
3 \\
\text { Unknown }\end{array}$ & $\begin{array}{l}89.8 \pm 3.5 \\
81.9 \pm 3.0 \\
63.1 \pm 3.6 \\
84.7 \pm 5.2\end{array}$ & $<0.001$ \\
\hline $\begin{array}{l}\text { FIGO stage } \\
\text { IIIC I (pelvic) } \\
\text { IIIC } 2 \text { (PALN with or without pelvic) }\end{array}$ & $\begin{array}{l}80.5 \pm 2.2 \\
67.0 \pm 4.0\end{array}$ & 0.001 \\
\hline $\begin{array}{l}\text { Number of positive nodes (average: } 3 \text {, range: } 1-82 \text { ) } \\
\quad>1\end{array}$ & $\begin{array}{l}79.5 \pm 2.6 \\
73.4 \pm 2.9\end{array}$ & 0.416 \\
\hline $\begin{array}{l}\text { Number of positive nodes (range: } 3 \text {, range: } 1-82 \text { ) } \\
\begin{array}{l}1 \\
2-5 \\
>5\end{array}\end{array}$ & $\begin{array}{l}79.5 \pm 2.6 \\
75.4 \pm 3.2 \\
62.9 \pm 7.3\end{array}$ & 0.016 \\
\hline $\begin{array}{l}\text { Total number of nodes examined (average: 17.3, rang } \\
\quad \leqslant 10 \\
11-20 \\
>20\end{array}$ & $\begin{array}{l}-90) \\
70.1 \pm 3.3 \\
81.7 \pm 3.3 \\
78.2 \pm 3.6\end{array}$ & 0.001 \\
\hline $\begin{array}{l}\text { Ratio of positive nodes (average: } 23.2 \% \text {, range: } 0.01 \text { - } \\
\quad \text {-Average } \\
>\text { Average }\end{array}$ & $\begin{array}{l}0 \%) \\
80.8 \pm 2.3 \\
67.6 \pm 3.6\end{array}$ & $<0.001$ \\
\hline $\begin{array}{l}\text { Ratio of positive nodes (average: } 23.2 \% \text {, range: } 0.01 \text { - } \\
\quad \leqslant 10 \\
10-50 \\
>50\end{array}$ & $\begin{array}{l}0 \%) \\
82.9 \pm 2.9 \\
73.9 \pm 2.9 \\
64.5 \pm 5.9\end{array}$ & $<0.001$ \\
\hline $\begin{array}{l}\text { Adjuvant radiation } \\
\text { No } \\
\text { Yes }\end{array}$ & $\begin{array}{l}67.0 \pm 3.7 \\
81.5 \pm 2.3\end{array}$ & $<0.001$ \\
\hline
\end{tabular}

Abbreviations: $\mathrm{DSS}=$ disease-specific survival; $\mathrm{PALN}=$ paraaortic lymph nodes. aMarital status: total $N=1054$ due to unknowns; not married includes single, divorced, separated, and widowed.

entering only one of the three lymph node parameters with age, marital status, grade, and adjuvant radiation therapy and showed all three nodal parameters were statistically significant. The ratio of positive lymph nodes as a continuous variable had the highest hazard ratio of $4.22, P<0.001$, compared with the hazard ratio for the location of positive nodes (1.49) and number of positive nodes (1.05).

A subset analysis was performed on those patients with one positive node $(n=487)$; of which $394(81.7 \%)$ had one positive pelvic node whereas $89(18.3 \%)$ had one positive paraaortic node (Supplementary Table S1). There was no significant difference in 3-year DSS for patients with one positive pelvic node compared with those with one positive paraaortic node $(80 \%$ vs $77.3 \%$, respectively, $P=0.675$, Figure 2$)$. These findings were confirmed on multivariate analysis (Supplementary Table S2).
The relative discriminatory ability of subgrouping patients with IIIC disease by location (IIIC $1 v s$ IIIC 2, number of positive nodes $(1 v s>1)$, and ratio of positive nodes $(\leqslant 23.2 \%$ vs $>23.2 \%)$ is shown in Supplementary Table S3. The hazard ratios for the ratio of positive nodes was 2.20, location (IIIC $1 v s$ IIIC 2) was 1.72 and 1 vs $>1$ positive nodes 1.15 (Table 5).

\section{DISCUSSION}

Uterine cancer is the most common gynaecologic malignancy in the United States with 43470 new cases and 7950 deaths expected for 2010 (Jemal et al, 2010). There has been an increase in the number of deaths, particularly in those with advanced stage (III/IV) disease (Ueda et al, 2008). Although the majority have excellent prognosis with 5-year survival rates between $80-91 \%$, the $\sim 5-10 \%$ of patients presenting with retroperitoneal lymph node involvement have inferior survival (Creasman et al, 2006; Lewin et al, 2010). Those with stage IIIC disease have survivals ranging from $10 \%$ to $75 \%$ (Chan et al, 2007). This, in part, reflects the heterogeneity in nodal and other prognostic parameters in stage IIIC cancers. The recent revision of FIGO staging of endometrial cancer has subdivided retroperitoneal node-positive patients into two subgroups based solely on the location of the positive nodes (Pecorelli, 2009).

Prior studies have shown a wide variation in survival based on lymph node location. In several series patients with involvement of pelvic lymph nodes only had nonsignificant differences in survival compared with those with positive paraaortic lymph nodes (McMeekin et al, 2001; Mariani et al, 2002; Otsuka et al, 2002; Havrilesky et al, 2005; Hoekstra et al, 2009; Lewin et al, 2010; Todo et al, 2011). In other series better survival was noted for patients with pelvic nodes (Morrow et al, 1991; Hirahatake et al, 1997; Yokoyama et al, 1997; Watari et al, 2005; Fujimoto et al, 2007; Karube et al, 2010; Lewin et al, 2010). Furthermore one recent series has shown a better survival for patients with positive paraaortic lymph nodes compared with those with positive pelvic lymph nodes ( $80 \%$ vs $55 \%$ at 5 years), although the difference was not statistically significant (Klopp et al, 2009). However, many of these studies did not account for the number of positive and ratio of positive nodes in addition to the location of positive nodes. Our current study analysed 1075 patients with endometrioid uterine cancer to confirm the independent prognostic significance of this new subgrouping based on node location. In addition, we compared the prognostic discrimination of nodal location with the number of positive and ratio of positive nodes.

Nodal location was found to be a significant prognostic factor both in univariate (Table 2, Figure 1A) and multivariate analysis when it was entered as the only term relating to the lymph nodes. However, the new subgrouping by nodal location was not shown to be statistically significant in multivariate analysis when the number of positive nodes and ratio of positive nodes were included (Table 4). As patients in our study with stage IIIC 2 disease had a higher number of positive lymph nodes than those with stage IIIC 1 disease ( 4.2 vs 2.0 , respectively, $P<0.001)$ we performed a separate analysis for those with only one positive retroperitoneal lymph node. This subgroup analysis showed no significant difference in DSS based on nodal location (Figure 2), while the ratio of positive nodes remained significant (Supplementary Table S2).

Our findings on the prognostic significance of the number of positive lymph nodes in univariate analysis (Figure 1B) confirm previous reports (Morrow et al, 1991; Takeshima et al, 1994; Touboul et al, 2001; Chan et al, 2007). Watari et al (2005) demonstrated a better 5-year survival rate for patients with one positive paraaortic lymph node group compared with those with $\geqslant 2$ positive paraaortic lymph node groups $(60.4 \%$ vs $20.0 \%$, respectively, $P=0.0319$ ) whereas Fujimoto et al (2009) reported 

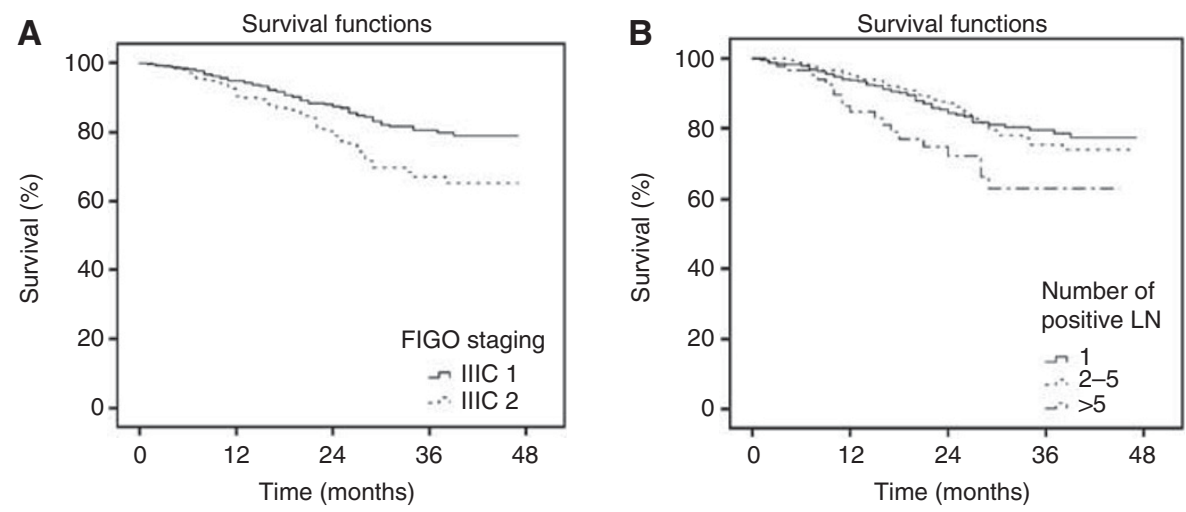

\begin{tabular}{|l|c|c|c|}
\hline Numbers at risk & $\begin{array}{c}12 \\
\text { months }\end{array}$ & $\begin{array}{c}24 \\
\text { months }\end{array}$ & $\begin{array}{c}36 \\
\text { months }\end{array}$ \\
\hline IIIC 1 (pelvic) & 497 & 268 & 115 \\
\hline $\begin{array}{l}\text { IIIC 2 (PALN with or } \\
\text { without pelvic) }\end{array}$ & 217 & 115 & 42 \\
\hline
\end{tabular}

\begin{tabular}{|c|c|c|c|}
\hline $\begin{array}{c}\text { Numbers at } \\
\text { risk }\end{array}$ & $\begin{array}{c}12 \\
\text { months }\end{array}$ & $\begin{array}{c}24 \\
\text { months }\end{array}$ & $\begin{array}{c}36 \\
\text { months }\end{array}$ \\
\hline 1 & 336 & 179 & 82 \\
\hline $2-5$ & 326 & 175 & 63 \\
\hline$>5$ & 51 & 28 & 11 \\
\hline
\end{tabular}

C

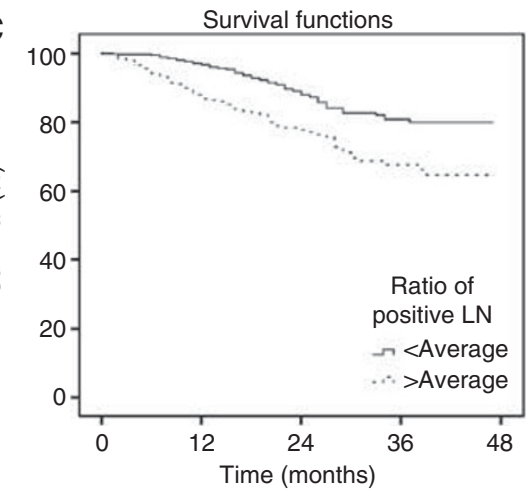

\begin{tabular}{|c|c|c|c|}
\hline Numbers at risk & $\begin{array}{c}12 \\
\text { months }\end{array}$ & $\begin{array}{c}24 \\
\text { months }\end{array}$ & $\begin{array}{c}36 \\
\text { months }\end{array}$ \\
\hline$\leq 23 \%$ & 496 & 259 & 107 \\
\hline$>23 \%$ & 219 & 124 & 50 \\
\hline
\end{tabular}

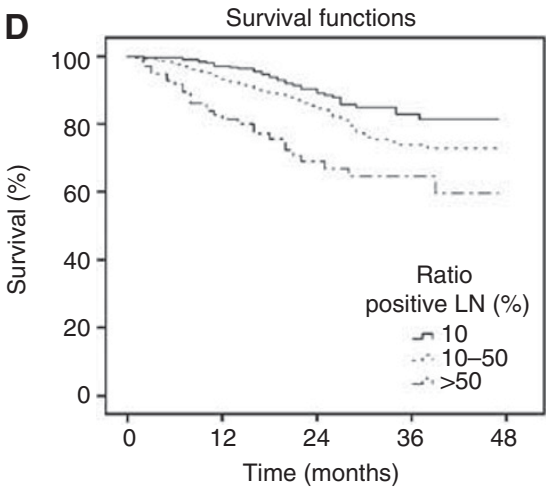

\begin{tabular}{|c|c|c|c|}
\hline Numbers at risk & $\begin{array}{c}12 \\
\text { months }\end{array}$ & $\begin{array}{c}24 \\
\text { months }\end{array}$ & $\begin{array}{c}36 \\
\text { months }\end{array}$ \\
\hline$\leq 10 \%$ & 276 & 151 & 66 \\
\hline $10-50 \%$ & 373 & 197 & 77 \\
\hline$>50 \%$ & 64 & 34 & 14 \\
\hline
\end{tabular}

Figure I Kaplan-Meier disease-specific survival of stage IIIC endometrioid uterine cancer based on the following: (A) FIGO stage IIIC I vs IIIIC 2; $P=0.00$ I. (B) Number (I vs $2-5$ vs $>5$ ) of positive lymph nodes; $P=0.016$. (C) Ratio of positive nodes $(\leqslant 23.2 \%$ vs $>23.2 \%)$, $P<0.00$ I. (D) Ratio of positive nodes ( $\leqslant 10 \%$ vs $10-50 \%$ vs $>50 \%$ ); $P<0.001$.

better 5-year relapse-free survival for patients with one positive pelvic lymph node site compared with those with $\geqslant 2$ positive sites $(81.3 \%$ vs $41.2 \%$, respectively, $P=0.04)$. We also showed the prognostic significance of the ratio of positive nodes to the total number of lymph nodes examined, which confirms our prior report (Chan et al, 2007). In the current study, the ratio of positive nodes was significant whether it was entered as a continuous variable in multivariate analysis, dichotomized at the mean of $23.2 \%$, or subgrouped based on $\leqslant 10 \%, 10-50 \%$, or $>50 \%$ involvement. The results from single institutional respective studies have also demonstrated the prognostic significance of ratio of positive lymph nodes (Tang et al, 1998; Mariani et al, 2001b).

Studies in other malignancies have also attempted to define the most prognostically significant subgroupings for lymph node positive patients. Various classification schemes for lymph nodes in gastric cancer have been based on the distance, number, and anatomical location of metastatic nodes as well as the site of the primary tumour (Kajitani, 1981; Hermanek and Sobin, 1992; Adachi et al, 1995; Sobin and Wittekind, 1997; de Manzoni et al, 1999). Classification of involved regional lymph nodes in gastric cancer by the ratio of positive nodes was found to represent a simple, reliable, and reproducible staging system (Yu et al, 1997;
Liu et al, 2007; Marchet et al, 2007; Persiani et al, 2008; Zhang et al, 2009; Maduekwe et al, 2010; Sianesi et al, 2010).

The major shortcoming of any substaging of endometrial cancer based on measurements of nodal involvement is the lack of standardisation of the lymphadenectomy. There is wide variation in the extent of nodal dissection reflecting both surgeon's bias and patient selection. For example, this could include performing a more limited lymph node dissection following a resection of an involved bulky node, or performing a more extensive nodal dissection in patients without bulky nodes or co-morbidities (Smith et al, 2008). The issue of standardisation of lymph node dissection has been thoroughly reviewed previously (Boronow, 1980; Kilgore et al, 1995; Chan and Kapp, 2007; Chang et al, 2008; Mariani et al, 2009). As discussed by Mariani et al (2009) in their commentary on the surgical staging of endometrial cancer, a standardisation of lymphadenectomy including the anatomical extent of the paraaortic lymph node dissection is lacking. The minimum requirement of lymphadenectomy, either in terms of nodal stations resected or total number of lymph nodes examined, has not been unambiguously defined in the FIGO staging system. Recommendations as to the minimum number of lymph nodes examined for adequate nodal staging have been in effect for colon cancer (12 nodes) (Nelson et al, 2001) 
Table 3 Comparison of characteristics between stage IIIC I and IIIC 2 patients

\begin{tabular}{|c|c|c|c|}
\hline Parameters & Stage IIIC I & Stage IIIC 2 & $P$-value \\
\hline \multicolumn{3}{|c|}{ Age (average: 62, range: 28-95) (years) } & \multirow[t]{3}{*}{0.410} \\
\hline$<62$ & $341(47.0 \%)$ & $174(49.7 \%)$ & \\
\hline$\geqslant 62$ & $384(53.0 \%)$ & $176(50.3 \%)$ & \\
\hline \multicolumn{3}{|l|}{ Marital status ${ }^{\mathrm{a}}$} & \multirow[t]{3}{*}{0.957} \\
\hline Married & $362(51.0 \%)$ & $176(51.2 \%)$ & \\
\hline Not married & $348(49.0 \%)$ & 168 & \\
\hline \multicolumn{3}{|l|}{ Race } & \multirow[t]{5}{*}{0.517} \\
\hline White & $619(85.4 \%)$ & $298(85.1 \%)$ & \\
\hline Black & $50(6.9 \%)$ & $18(5.1 \%)$ & \\
\hline Asian & $49(6.8 \%)$ & $30(8.6 \%)$ & \\
\hline Unknown or other & $7(1.0 \%)$ & $4(1.1 \%)$ & \\
\hline \multicolumn{3}{|l|}{ Grade } & \multirow[t]{5}{*}{0.008} \\
\hline 1 & $118(16.3 \%)$ & $51(14.6 \%)$ & \\
\hline 2 & $304(41.9 \%)$ & $125(35.7 \%)$ & \\
\hline 3 & $243(33.5 \%)$ & I54 (44.0\%) & \\
\hline Unknown & $60(8.3 \%)$ & $20(5.7 \%)$ & \\
\hline \multicolumn{3}{|c|}{ Number of positive nodes (range: 3, range: I-82) } & \multirow[t]{4}{*}{$<0.001$} \\
\hline & $398(54.9 \%)$ & $89(25.4 \%)$ & \\
\hline $2-5$ & $303(41.8 \%)$ & $188(53.7 \%)$ & \\
\hline$>5$ & $24(3.3 \%)$ & $73(20.9 \%)$ & \\
\hline \multirow{4}{*}{\multicolumn{3}{|c|}{$\begin{array}{lll}\text { Total number of nodes examined (average: } 17.3, \text { range: } & 1-90) \\
\quad \leqslant 10 & 272(37.5 \%) & 104(29.7 \%) \\
11-20 & 246(33.9 \%) & 100(28.6 \%) \\
>20 & 207(28.6 \%) & 146(41.7 \%)\end{array}$}} & \multirow[t]{4}{*}{$<0.001$} \\
\hline & & & \\
\hline & & & \\
\hline & & & \\
\hline \multicolumn{3}{|c|}{ Ratio of positive nodes (average: $23.2 \%$, range: $0.01-100 \%$ ) } & \multirow[t]{3}{*}{0.001} \\
\hline$\leqslant$ Average & $515(71.0 \%)$ & $214(61.1 \%)$ & \\
\hline$>$ Average & $210(29.0 \%)$ & $136(3$ & \\
\hline \multicolumn{3}{|c|}{ Ratio of positive nodes (average: $23.2 \%$, range: $0.01-100 \%$ ) } & \multirow[t]{4}{*}{$<0.001$} \\
\hline$\leqslant 10$ & $306(42.2 \%)$ & $96(27.4 \%)$ & \\
\hline $10-50$ & $36 \mid(49.8 \%)$ & $206(58.9 \%)$ & \\
\hline$>50$ & $58(8.0 \%)$ & $48(13.7 \%)$ & \\
\hline \multicolumn{3}{|l|}{ Adjuvant radiation } & \multirow[t]{3}{*}{0.060} \\
\hline No & $444(61.2 \%)$ & 194 (55.4\%) & \\
\hline Yes & $281(38.8 \%)$ & $156(44.6 \%)$ & \\
\hline \multicolumn{3}{|l|}{ Number positive nodes } & \multirow[t]{4}{*}{$<0.001^{b}$} \\
\hline Mean & 2.0 & 4.2 & \\
\hline Median & 1 & 1 & \\
\hline Range & $1-16$ & $1-82$ & \\
\hline \multicolumn{3}{|l|}{ Total number of nodes examined } & \multirow[t]{4}{*}{$<0.001^{b}$} \\
\hline Mean & 15.8 & 20.6 & \\
\hline Median & 14 & 16 & \\
\hline Range & $1-88$ & $1-90$ & \\
\hline \multicolumn{3}{|l|}{ Ratio of positive nodes } & \multirow[t]{3}{*}{$0.001^{\mathrm{b}}$} \\
\hline Mean & $21.5 \%$ & $26.8 \%$ & \\
\hline Median & $12.5 \%$ & $18.2 \%$ & \\
\hline
\end{tabular}

a Marital Status: total $N=1054$ due to unknowns; not married includes single, divorced, separated, and widowed. ${ }^{\mathrm{b} P}$-values are based on independent sample $t$-test.

and gastric cancer (15 nodes) (Green et al, 2010). We are in agreement with the NCCN guidelines for the treatment of uterine cancer recommending a complete pelvic and paraaortic lymphadenectomy (unless technically unfeasible or medically contraindicated), adhering to the ACOG surgical policy (ACOG, 2005).

Two prospective randomized trials have failed to demonstrate a survival advantage from pelvic lymphadenectomy in endometrial cancer (Benedetti Panici et al, 2008; Kitchener et al, 2009). However the inclusion of low-risk patients, lack of standardisation of systemic postoperative treatments, and minimal or lack of paraaortic lymphadenectomy are limitations of these studies
Table 4 Multivariate analysis for prognostication for disease-specific survival for stage IIIC endometrioid uterine cancer $(n=1075)$

\begin{tabular}{lccr}
\hline Factor & $\begin{array}{c}\text { Hazard } \\
\text { ratio }\end{array}$ & $\begin{array}{c}\mathbf{9 5 \%} \text { confidence } \\
\text { interval }\end{array}$ & P-value \\
\hline Age of diagnosis $^{\mathrm{a}}$ & 1.01 & $1.00-1.02$ & 0.170 \\
Grade $^{\mathrm{b}}$ & 2.19 & $1.62-2.96$ & $<0.001$ \\
${\text { Location of } \mathrm{LN}^{\mathrm{c}}}^{\mathrm{N}}$ & 1.27 & $0.87-1.84$ & 0.218 \\
Number of positive nodes $^{\mathrm{d}}$ & 1.04 & $1.00-1.08$ & 0.065 \\
Number of $\mathrm{LN} \mathrm{examined}^{\mathrm{e}}$ & 0.99 & $0.97-1.01$ & 0.507 \\
Ratio of positive nodes $^{\mathrm{f}}$ & 3.10 & $1.41-6.81$ & 0.005 \\
Adjuvant radiationg $^{\mathrm{g}}$ & 0.47 & $0.33-0.66$ & $<0.001$ \\
Marital status $^{\mathrm{h}}$ & 0.63 & $0.44-0.90$ & 0.010 \\
\hline
\end{tabular}

Abbreviation: $\mathrm{LN}=$ lymph node. ${ }^{\mathrm{a}}$ Age at diagnosis as a continuous variable. ${ }^{\mathrm{b}} \mathrm{Grade}$ as I vs 2 vs 3 (undetermined grade excluded). 'Location of positive nodes as pelvic vs paraaortic with or without pelvic. Number of positive lymph nodes as a continuous

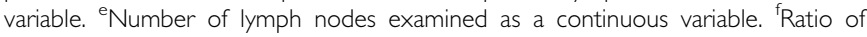
positive lymph nodes as a continuous variable. "No adjuvant radiation vs administration of adjuvant radiation. "hNot married (including single, divorced, widowed, separated) vs married.

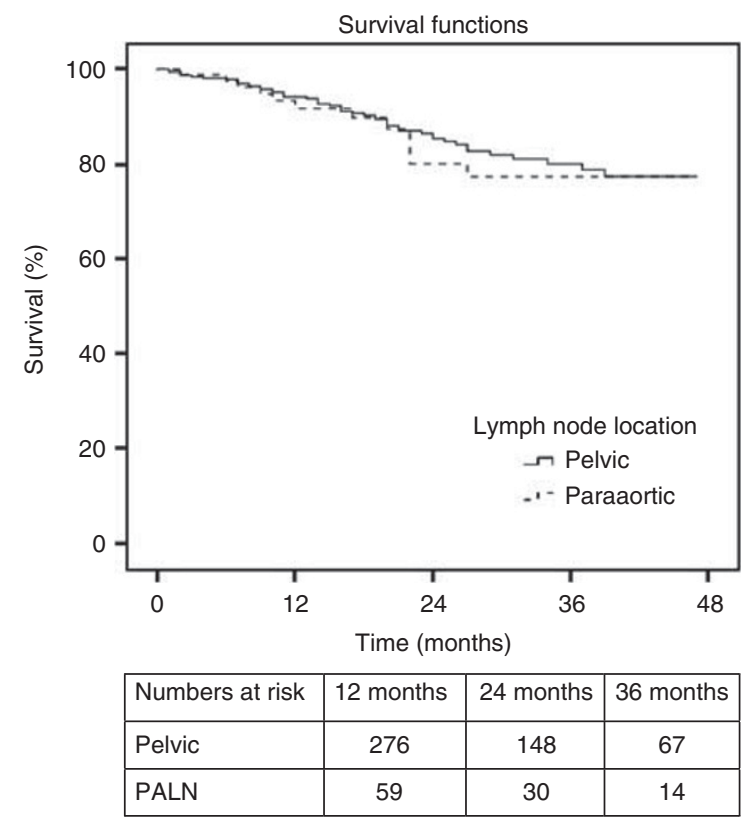

Figure 2 Kaplan-Meier disease-specific survival for stage IIIC endometrioid cancer patients $(n=487)$ with only one positive node based on lymph node location (pelvic vs paraaortic); $P=0.675$.

(Amant et al, 2009; Uccella et al, 2009; Seamon et al, 2010). A recent retrospective study in patients with stage III C endometrial cancer demonstrated the therapeutic significance of systematic lymphadenectomy including both pelvic and paraaortic node dissection (Todo et al, 2011).

Additional limitations of our study include the lack of information on other patient and treatment factors that may be of prognostic significance in patients with retroperitoneal node involvement. In particular, there is a lack of information on the extent of the pelvic and/or paraaortic lymphadenopathy, the extent of surgical staging, the surgeon's subspecialty, the extent of lymph node debulking, involvement of other pelvic extrauterine sites including the adnexa and peritoneal cytology, involvement of the uterine cervix, depth of myometrial invasion, lymph vascular space invasion, and size of the lymph nodes. Our study was limited to patients with endometrioid histology, relatively short follow-up, and there was no central pathology review. There is also a lack of information on sites of recurrence and the use of adjuvant systemic chemotherapy and hormonal therapy. However, the 
Table 5 Cox regression models for disease-specific survival for subgrouping by location, number, and ratio of positive lymph nodes in stage IIIC endometrioid uterine cancer patients

\begin{tabular}{|c|c|c|c|c|c|c|c|c|}
\hline Stage & $\begin{array}{l}\text { Hazard } \\
\text { ratio }\end{array}$ & $95 \% \mathrm{Cl}$ & $\begin{array}{c}\text { Number of } \\
\text { positive nodes }\end{array}$ & Hazard ratio & $95 \% \mathrm{Cl}$ & $\begin{array}{c}\text { Ratio of } \\
\text { positive nodes }\end{array}$ & $\begin{array}{l}\text { Hazard } \\
\text { ratio }\end{array}$ & $95 \% \mathrm{Cl}$ \\
\hline IIIC I & 1 & - & I & I & - & $\leqslant 23.2 \%$ & I & - \\
\hline IIIC 2 & 1.72 & $1.23-2.4 \mid$ & $>1$ & 1.15 & $0.82-1.60$ & $>23.2 \%$ & 2.20 & $1.58-3.06$ \\
\hline Continuous variable & NA & NA & Continuous variable & 1.04 & $1.02-1.06$ & Continuous variable & 4.47 & $2.66-7.54$ \\
\hline
\end{tabular}

Abbreviations: $\mathrm{Cl}=$ confidence interval; $\mathrm{NA}=$ not applicable.

recent years of diagnosis of the patients included in this study should make them more likely to have received adjuvant treatment with chemotherapy or volume-directed radiation therapy and chemotherapy than studies including earlier cohorts of SEER patients. Other general limitations of SEER-based research including variation in data registry, underreporting of radiation therapy, lack of details on adjuvant radiation therapy (fields treated and doses), and selection bias have recently been reviewed by $\mathrm{Yu}$ et al (2009).

The strengths of our analysis include the large number of recently diagnosed patients with node-positive endometrioid uterine cancers studied within a wide geographic distribution in the United States. In addition, our univariate and multivariate analysis of the three major subgroupings of stage IIIC patients (based on the new FIGO substaging, number of positive lymph nodes reported, and lymph node ratio) has permitted identification of the subgroupings with better abilities to discriminate DSS in this heterogeneous group of stage IIIC patients.

In summary, better classification of retroperitoneal lymph node-positive endometrioid uterine cancer patients may permit the identification of more homogenous subgroupings for prognostic purposes, stratification in clinic trials, and possible better selection for individualised adjuvant-combined modality treatments (Mariani et al, 2004). Higher risk subgroups, for example those with multiple pelvic and paraaortic nodal involvement, may require more intense chemotherapy regimens, whereas those with limited nodal disease may best be managed with volumedirected radiation therapy and less toxic systemic treatment protocols. Our study has confirmed the value of subgrouping stage IIIC patients based on nodal location, number of positive lymph nodes and ratio of positive nodes. However based on multivariate and discrimination analyses, nodal ratio was a stronger discriminator for DSS than nodal location, controlling for other confounding factors including tumor grade and the use of adjuvant radiation therapy. If our results are validated in other patient databases, these findings may permit better modifications of the substaging of retroperitoneal lymph node positive patients. However, it is stressed that standardisation of lymphadenectomy including the boundaries of resection, uniform processing of the nodal specimens, and the criteria for adequacy of lymph node resection are needed.

Supplementary Information accompanies the paper on British Journal of Cancer website (http://www.nature.com/bjc)

\section{REFERENCES}

ACOG (2005) ACOG practice bulletin, clinical management guidelines for obstetrician-gynecologists, number 65, August 2005: management of endometrial cancer. Obstet Gynecol 106: 413-425

Adachi Y, Oshiro T, Okuyama T, Kamakura T, Mori M, Maehara Y, Sugimachi K (1995) A simple classification of lymph node level in gastric carcinoma. Am J Surg 169: $382-385$

Amant F, Neven P, Vergote I (2009) Lymphadenectomy in endometrial cancer. Lancet 373: 1169-1170; author reply 1170-1171

Benedetti Panici P, Basile S, Maneschi F, Alberto Lissoni A, Signorelli M, Scambia G, Angioli R, Tateo S, Mangili G, Katsaros D, Garozzo G, Campagnutta E, Donadello N, Greggi S, Melpignano M, Raspagliesi F, Ragni N, Cormio G, Grassi R, Franchi M, Giannarelli D, Fossati R, Torri V, Amoroso M, Croce C, Mangioni C (2008) Systematic pelvic lymphadenectomy $v s$ no lymphadenectomy in early-stage endometrial carcinoma: randomized clinical trial. J Natl Cancer Inst 100: 1707-1716

Boronow RC (1980) Staging of endometrial cancer. Int J Radiat Oncol Biol Phys 6: $355-359$

Chan JK, Kapp DS (2007) Role of complete lymphadenectomy in endometrioid uterine cancer. Lancet Oncol 8: $831-841$

Chan JK, Kapp DS, Cheung MK, Osann K, Shin JY, Cohn D, Seid PL (2007) The impact of the absolute number and ratio of positive lymph nodes on survival of endometrioid uterine cancer patients. Br J Cancer 97: $605-611$

Chang SJ, Kim WY, Yoon JH, Yoo SC, Chang KH, Ryu HS (2008) Paraaortic lymphadenectomy improves survival in patients with intermediate to high-risk endometrial carcinoma. Acta Obstet Gynecol Scand 87: $1361-1369$

Cooke EW, Pappas L, Gaffney DK (2011) Does the revised international federation of gynecology and obstetrics staging system for endometrial cancer lead to increased discrimination in patient outcomes? Cancer; e-pub ahead of print 8 March 2011
Creasman WT, Morrow CP, Bundy BN, Homesley HD, Graham JE, Heller PB (1987) Surgical pathologic spread patterns of endometrial cancer. A Gynecologic Oncology Group Study. Cancer 60: 2035-2041

Creasman WT, Odicino F, Maisonneuve P, Quinn MA, Beller U, Benedet JL, Heintz AP, Ngan HY, Pecorelli S (2006) Carcinoma of the corpus uteri. FIGO 26th annual report on the results of treatment in gynecological cancer. Int J Gynaecol Obstet 95(Suppl 1): S105-S143

de Manzoni G, Verlato G, Guglielmi A, Laterza E, Tomezzoli A, Pelosi G, Di Leo A, Cordiano C (1999) Classification of lymph node metastases from carcinoma of the stomach: comparison of the old (1987) and new (1997) TNM systems. World J Surg 23: 664-669

Fujimoto T, Nanjyo H, Fukuda J, Nakamura A, Mizunuma H, Yaegashi N, Sugiyama T, Kurachi H, Sato A, Tanaka T (2009) Endometrioid uterine cancer: histopathological risk factors of local and distant recurrence. Gynecol Oncol 112: $342-347$

Fujimoto T, Nanjyo H, Nakamura A, Yokoyama Y, Takano T, Shoji T, Nakahara K, Yamada H, Mizunuma H, Yaegashi N, Sugiyama T, Kurachi H, Sato A, Tanaka T (2007) Para-aortic lymphadenectomy may improve disease-related survival in patients with multipositive pelvic lymph node stage IIIc endometrial cancer. Gynecol Oncol 107: 253-259

Gimotty PA, Botbyl J, Soong SJ, Guerry D (2005) A population-based validation of the American Joint Committee on cancer melanoma staging system. J Clin Oncol 23: 8065-8075

Green FL, Trotti III A, Fritz AG, Compton, CC, Byrd, DR, Edge SB (2010) AJCC Cancer Staging Handbook 7th edn, Chicago, IL

Havrilesky LJ, Cragun JM, Calingaert B, Synan I, Secord AA, Soper JT, Clarke-Pearson DL, Berchuck A (2005) Resection of lymph node metastases influences survival in stage IIIC endometrial cancer. Gynecol Oncol 99: 689-695

Hermanek P, Sobin LH (1992) TNM Classification of Malignant Tumours p 217. Springer-Verlag: Berlin; New York 
Hirahatake K, Hareyama H, Sakuragi N, Nishiya M, Makinoda S, Fujimoto S (1997) A clinical and pathologic study on para-aortic lymph node metastasis in endometrial carcinoma. J Surg Oncol 65: 82-87

Hoekstra AV, Kim RJ, Small Jr W, Rademaker AW, Helenowski IB, Singh DK, Schink JC, Lurain JR (2009) FIGO stage IIIC endometrial carcinoma: prognostic factors and outcomes. Gynecol Oncol 114: 273-278

Jemal A, Siegel R, Xu J, Ward E (2010) Cancer statistics, 2010. CA Cancer J Clin 60: $277-300$

Kajitani T (1981) The general rules for the gastric cancer study in surgery and pathology. Part I. Clinical classification. Jpn J Surg 11: 127-139

Karube Y, Fujimoto T, Takahashi O, Nanjyo H, Mizunuma H, Yaegashi N, Sugiyama T, Kurachi H, Sato A, Tanaka T (2010) Histopathological prognostic factors predicting para-aortic lymph node metastasis in patients with endometrioid uterine cancer. Gynecol Oncol 118: 151-154

Kilgore LC, Partridge EE, Alvarez RD, Austin JM, Shingleton HM, Noojin 3rd F, Conner W (1995) Adenocarcinoma of the endometrium: survival comparisons of patients with and without pelvic node sampling. Gynecol Oncol 56: $29-33$

Kitchener H, Swart AM, Qian Q, Amos C, Parmar MK (2009) Efficacy of systematic pelvic lymphadenectomy in endometrial cancer (MRC ASTEC trial): a randomised study. Lancet 373: $125-136$

Klopp AH, Jhingran A, Ramondetta L, Lu K, Gershenson DM, Eifel PJ (2009) Node-positive adenocarcinoma of the endometrium: outcome and patterns of recurrence with and without external beam irradiation. Gynecol Oncol 115: 6-11

Lewin SN, Herzog TJ, Barrena Medel NI, Deutsch I, Burke WM, Sun X, Wright JD (2010) Comparative performance of the 2009 international Federation of gynecology and obstetrics' staging system for uterine corpus cancer. Obstet Gynecol 116: 1141-1149

Liu C, Lu P, Lu Y, Xu H, Wang S, Chen J (2007) Clinical implications of metastatic lymph node ratio in gastric cancer. BMC Cancer 7: 200

Maduekwe UN, Lauwers GY, Fernandez-Del-Castillo C, Berger DL, Ferguson CM, Rattner DW, Yoon SS (2010) New metastatic lymph node ratio system reduces stage migration in patients undergoing D1 lymphadenectomy for gastric adenocarcinoma. Ann Surg Oncol 17: 1267-1277

Marchet A, Mocellin S, Ambrosi A, Morgagni P, Garcea D, Marrelli D, Roviello F, de Manzoni G, Minicozzi A, Natalini G, De Santis F, Baiocchi L, Coniglio A, Nitti D (2007) The ratio between metastatic and examined lymph nodes ( $\mathrm{N}$ ratio) is an independent prognostic factor in gastric cancer regardless of the type of lymphadenectomy: results from an Italian multicentric study in 1853 patients. Ann Surg 245: $543-552$

Mariani A, Dowdy SC, Podratz KC (2009) New surgical staging of endometrial cancer: 20 years later. Int J Gynaecol Obstet 105: 110-111

Mariani A, Keeney GL, Aletti G, Webb MJ, Haddock MG, Podratz KC (2004) Endometrial carcinoma: paraaortic dissemination. Gynecol Oncol 92: $833-838$

Mariani A, Webb MJ, Keeney GL, Aletti G, Podratz KC (2002) Assessment of prognostic factors in stage IIIA endometrial cancer. Gynecol Oncol 86: $38-44$

Mariani A, Webb MJ, Keeney GL, Podratz KC (2001a) Routes of lymphatic spread: a study of 112 consecutive patients with endometrial cancer. Gynecol Oncol 81: 100-104

Mariani A, Webb MJ, Rao SK, Lesnick TG, Podratz KC (2001b) Significance of pathologic patterns of pelvic lymph node metastases in endometrial cancer. Gynecol Oncol 80: 113-120

McMeekin DS, Lashbrook D, Gold M, Johnson G, Walker JL, Mannel R (2001) Analysis of FIGO stage IIIc endometrial cancer patients. Gynecol Oncol 81: 273-278

Morrow CP, Bundy BN, Kurman RJ, Creasman WT, Heller P, Homesley HD, Graham JE (1991) Relationship between surgical-pathological risk factors and outcome in clinical stage I and II carcinoma of the endometrium: a Gynecologic Oncology Group study. Gynecol Oncol 40: $55-65$

Nelson H, Petrelli N, Carlin A, Couture J, Fleshman J, Guillem J, Miedema B, Ota D, Sargent D (2001) Guidelines 2000 for colon and rectal cancer surgery. J Natl Cancer Inst 93: 583 - 596
Otsuka I, Kubota T, Aso T (2002) Lymphadenectomy and adjuvant therapy in endometrial carcinoma: role of adjuvant chemotherapy. Br J Cancer 87: $377-380$

Pecorelli S (2009) Revised FIGO staging for carcinoma of the vulva, cervix, and endometrium. Int J Gynaecol Obstet 105: 103-104

Persiani R, Rausei S, Biondi A, Boccia S, Cananzi F, D’Ugo D (2008) Ratio of metastatic lymph nodes: impact on staging and survival of gastric cancer. Eur J Surg Oncol 34: 519-524

Seamon LG, Fowler JM, Cohn DE (2010) Lymphadenectomy for endometrial cancer: the controversy. Gynecol Oncol 117: 6-8

SEER (2010) SEER ${ }^{\star S t a t}$ Database: incidence SEER 17 Registries Database, Public Use, 2004-2007 vol. 2010. National Cancer Institute, DCCPS, Surveillence Research Program, Cancer Statistics Branch URL: http:// www.seer.cancer.gov

Sianesi M, Bezer L, Del Rio P, Dell'Abate P, Iapichino G, Soliani P, Tacci S (2010) The node ratio as prognostic factor after curative resection for gastric cancer. J Gastrointest Surg 14: 614-619

Smith DC, Macdonald OK, Lee CM, Gaffney DK (2008) Survival impact of lymph node dissection in endometrial adenocarcinoma: a surveillance, epidemiology, and end results analysis. Int J Gynecol Cancer 18: 255-261

Sobin LH, Wittekind CH (1997) TMN Classification of Malignant Tumors $\mathrm{p}$ 227. J. Wiley: New York

Takeshima N, Umayahara K, Fujiwara K, Hirai Y, Takizawa K, Hasumi K (2006) Effectiveness of postoperative chemotherapy for para-aortic lymph node metastasis of endometrial cancer. Gynecol Oncol 102: $214-217$

Takeshima N, Umezawa S, Shimizu Y, Fujimoto I, Yamauchi K, Hasumi K (1994) Pelvic lymph node metastasis in endometrial cancer. Nippon Sanka Fujinka Gakkai Zasshi 46: $883-888$

Tang X, Tanemura K, Ye W, Ohmi K, Tsunematsu R, Yamada T, Katsumata N, Sonoda T (1998) Clinicopathological factors predicting retroperitoneal lymph node metastasis and survival in endometrial cancer. Jpn J Clin Oncol 28: 673-678

Todo Y, Kato H, Minobe S, Okamoto K, Suzuki Y, Konno Y, Takeda M, Watari H, Kaneuchi M, Sakuragi N (2011) A validation study of the new revised FIGO staging system to estimate prognosis for patients with stage IIIC endometrial cancer. Gynecol Oncol 121: 126-130

Touboul E, Belkacemi Y, Buffat L, Deniaud-Alexandre E, Lefranc JP, Lhuillier P, Uzan S, Jannet D, Uzan M, Antoine M, Huart J, Ganansia V, Milliez J, Blondon J, Housset M, Schlienger M (2001) Adenocarcinoma of the endometrium treated with combined irradiation and surgery: study of 437 patients. Int J Radiat Oncol Biol Phys 50: 81-97

Uccella S, Podratz KC, Aletti GD, Mariani A (2009) Lymphadenectomy in endometrial cancer. Lancet 373: 1170; author reply 1170-1171

Ueda SM, Kapp DS, Cheung MK, Shin JY, Osann K, Husain A, Teng NN, Berek JS, Chan JK (2008) Trends in demographic and clinical characteristics in women diagnosed with corpus cancer and their potential impact on the increasing number of deaths. Am J Obstet Gynecol 198: 218 e1-6

Watari H, Todo Y, Takeda M, Ebina Y, Yamamoto R, Sakuragi N (2005) Lymph-vascular space invasion and number of positive para-aortic node groups predict survival in node-positive patients with endometrial cancer. Gynecol Oncol 96: 651-657

Yasunaga M, Yamasaki F, Tokunaga O, Iwasaka T (2003) Endometrial carcinomas with lymph node involvement: novel histopathologic factors for predicting prognosis. Int J Gynecol Pathol 22: $341-346$

Yokoyama Y, Maruyama H, Sato S, Saito Y (1997) Risk factors predictive of para-aortic lymph node metastasis in endometrial carcinomas. J Obstet Gynaecol Res 23: 179-187

Yu JB, Gross CP, Wilson LD, Smith BD (2009) NCI SEER public-use data: applications and limitations in oncology research. Oncology (Williston Park) 23: 288-295

Yu W, Choi GS, Whang I, Suh IS (1997) Comparison of five systems for staging lymph node metastasis in gastric cancer. Br J Surg 84: $1305-1309$

Zhang M, Zhu G, Ma Y, Xue Y (2009) Comparison of four staging systems of lymph node metastasis in gastric cancer. World J Surg 33: 2383-2388

This work is published under the standard license to publish agreement. After 12 months the work will become freely available and the license terms will switch to a Creative Commons Attribution-NonCommercial-Share Alike 3.0 Unported License. 